\title{
Uveal Melanoma—Clinical and Pathological Update
}

\author{
Zélia Maria S Corrêa, MD, PhD¹ and James Jay Augsburger, MD² \\ 1. Mary Knight Asbury Chair of Ophthalmic Pathology and Associate Professor; 2. E Vernon and Eloise C Smith Chair, \\ Professor, and Chairman, Department of Ophthalmology, \\ University of Cincinnati College of Medicine
}

\begin{abstract}
Although ocular treatments of the primary uveal melanoma are effective to eradicate the primary tumor locally, its impact on survival remains unclear. The reason we believe local treatment has limited or no impact on survival is because, despite the increase in diagnostic accuracy over the past several decades and development of globe-sparing treatments, the mortality rates of patients with uveal melanomas of any given size have not changed appreciably during this period. Development of metastases is a complex multi-step process that occurs almost exclusively via a hematogenous route. Due to the complexity of this process it is difficult to isolate individual events in patients that are important in the overall progression of the disease from primary tumor to metastasis. Because most uveal melanomas are currently managed by eye-preserving methods that do not yield a pathologic specimen, a number of investigators are currently performing biopsy (usually fine needle aspiration biopsy) of these tumors prior to, or at the time of, ocular treatment to obtain representative tumor specimens for cytopathologic, cytogenetic, and/or molecular biologic analysis. Many new discoveries about the cytogenetic and molecular biologic abnormalities in uveal melanoma cells, and the ways these features influence development and prognosis of metastatic tumors have been published. Hopefully these findings will help us understand the process and improve patient survival since the impact of surveillance testing for metastasis and systemic therapy on the survival of patients with metastatic uveal melanoma is still uncertain.
\end{abstract}

\section{Keywords}

Uveal melanoma, fine needle aspiration biopsy, cytogenetic, gene expression profile, metastasis, surveillance testing for metastasis, treatment for metastasis

Disclosure: The authors have no conflicts of interest to declare.

Received: May 1, 2011 Accepted: January 6, 2012 Citation: US Ophthalmic Review, 2012;5(1)59-61 DOI: 10.17925/USOR.2012.05.01.59

Correspondence: Zelia M Correa, MD, PhD, Deptartment of Ophthalmology, University of Cincinnati College of Medicine, 260 Stetson Street, Suite 5300, PO Box 670527,

Cincinnati, OH 45267-0527. E: correazm@uc.edu

Uveal melanoma is the most common primary intraocular tumor in adults and often results not only in vision loss but also in metastatic death., ${ }^{1,2}$ The goals of ocular treatment of the primary uveal melanoma are: to prevent, or reduce the risk of, metastasis; to prevent further growth of the tumor and destruction of ocular tissues; to preserve as much vision as possible; and to achieve a cosmetically acceptable appearance. Although reducing the risk of metastasis is the foremost goal, the impact of local tumor treatment on survival remains unclear. The reason we believe local treatment has limited or no impact on survival is because, despite the increase in diagnostic accuracy over the past several decades and development of globe-sparing treatments such as plaque radiotherapy, proton beam irradiation, and local resection, the mortality rates of patients with uveal melanomas of any given size have not changed appreciably during this period. ${ }^{3}$

\section{Uveal Melanoma-From Local to Systemic Disease}

In patients who develop metastasis from primary uveal melanoma, the liver is usually the first site of clinically detectable metastasis; however, some patients present with extrahepatic metastasis and a substantial proportion eventually develop metastatic tumors in sites such as lungs and bones. The development of metastases is a complex multi-step process that occurs almost exclusively via a hematogenous route. A cell must be capable of detaching from the primary tumor, and subsequently invade through the extracellular matrix and blood vessel walls to enter the bloodstream, survive in the systemic circulation, implant, and then proliferate at the site of metastasis. This entire chain of events has been described as the metastatic cascade. ${ }^{4}$ Due to the complexity of this process it is difficult to isolate individual events in patients that are important in the overall progression of the disease from primary tumor to metastasis.

Multiple clinical, histopathologic, cytogenetic, and molecular biologic factors related to the prognosis of uveal melanoma have been identified. Clinical features associated with metastatic death include larger tumor size, involvement of the ciliary body, older patient age, and extrascleral tumor extension. ${ }^{5}$ Histopathologic features associated 
with poor prognosis include epithelioid cell type, extracellular matrix pattern, mitotic figures, heterogeneous nuclear and nucleolar size, and tumor infiltration by macrophages and/or lymphocytes..$^{6-8}$ Cytogenetic factors associated with poor prognosis include monosomy 3 and gain of chromosome 8q. ${ }^{9-11}$ Molecular biologic factors associated with poor prognosis include class 2 gene expression profile ${ }^{12}$ and overexpression or underexpression of specific genes. ${ }^{13}$

Because most uveal melanomas are currently managed by eye-preserving methods such as plaque and proton beam radiotherapy that do not yield a pathologic specimen, a number of investigators are currently performing biopsy (usually fine needle aspiration biopsy [FNAB]) ${ }^{14}$ of uveal melanomas prior to, or at the time of, ocular treatment to obtain representative tumor specimens for cytopathologic, cytogenetic, and/or molecular biologic analysis. Gene expression profiling of tumor cells seems to distinguish accurately between tumors having low metastatic potential (class 1 signature) from those who also have a short term low metastatic potential but slightly higher mid to long term risk (class 1B), and those having short term high metastatic potential (class 2 signature). ${ }^{16}$ Gene expression profile assays use a RT-PCR to determine the expression of a panel of 15 genes, three of them controls, in the tumor sample. This assay can be performed in fresh/frozen tumor aspirates or paraffin preserved tissue. ${ }^{16}$

\section{The Melanoma Molecular Map Project}

In recent years, many new discoveries about the cytogenetic and molecular biologic abnormalities in uveal melanoma cells, and the ways these features influence development and prognosis of metastatic tumors, have been published. ${ }^{12,16,17}$ Because of the sheer volume of information available in multiple scientific journals, no single clinician or basic scientist can keep up with all of this information. This circumstance allows us to suppose we may already have the pieces of information necessary to solve the puzzle of metastatic uveal melanoma but have not done so because of the complexity of putting them together. ${ }^{18}$ The Melanoma Molecular Map Project college website (www.mmmp.org) was launched recently as an ambitious non-profit initiative to enable the scientific community dedicated to melanoma research to gather and share the ever-growing published knowledge on melanoma in a systematic fashion and in a translational perspective. Hopefully, this initiative will lead us closer to solving our puzzle and in turn ultimately lead to improved patient survival.

\section{Treatment of Metastatic Uveal Melanoma}

Unfortunately, the impact of systemic therapy on the survival of patients with metastatic uveal melanoma is uncertain. Metastatic uveal melanoma has a dismal track record of responding to conventional intravenous chemotherapy. ${ }^{16-20}$ Most chemotherapy regimens that have been evaluated in prospective Phase I or Phase II clinical trials of metastatic uveal melanoma have produced few, if any, sustained objective favorable responses, ${ }^{19}$ and no chemotherapy regimen has been shown to prolong survival of patients with metastatic uveal melanoma in a randomized Phase III clinical trial. ${ }^{20}$ Unfortunately, chemotherapy is about the only anticancer therapy that can be offered to most patients with widespread metastatic disease..$^{21}$

In patients with a limited substage of metastatic uveal melanoma (e.g., single or few metastatic tumors, small tumors, single organ involvement), aggressive local-regional treatments such as hepatic artery infusion chemotherapy with or with embolization (if the liver is the only involved site of metastasis) ${ }^{22-27}$ or surgical metastasectomy ${ }^{28-30}$ are frequently employed as first-line therapy in certain centers. While metastasectomy clearly reduces the tumor burden and hepatic artery infusion chemotherapy induces an objective response in a substantially higher percentage of patients with uveal melanoma metastasis than does intravenous chemotherapy, ${ }^{21-23}$ neither method of treatment has ever been evaluated in a randomized Phase III clinical trial that included untreated, placebo-treated, sham-treated, or intravenous chemotherapy-treated patients with a similar limited substage of metastatic uveal melanoma. Consequently, the magnitude of any survival benefit of such treatments (if one exists at all) cannot be determined at present.

Although the median survival of selected groups of patients with limited substage metastatic uveal melanoma subjected to metastasectomy or hepatic infusion chemotherapy is usually substantially longer than the median survival of unselected groups of patients with advanced symptomatic metastatic uveal melanoma treated by intravenous chemotherapy or supportive care only, factors such as selection bias and surveillance bias are likely to explain much, if not all, of this difference..$^{20}$

\section{Adjuvant Therapy for Patients with Uveal Melanoma}

In spite of the absence of compelling scientific evidence of any substantial survival benefit of any method of treatment for any substage of metastatic uveal melanoma at this time, several adjuvant therapy trials of different agents (including imatinib mesylate, ${ }^{24}$ bortezomib, vorinostat, sorafenib, sunitinib, vascular endothelial growth factor (VEGF) Trap, ${ }^{25}$ AZD2171, ${ }^{26}$ and lenalidomide) have been initiated in recent years in an attempt to prevent or delay the emergence of clinically detectable metastasis from primary uveal melanoma (see www.clinicaltrials.gov). Unfortunately, because none of the agents being tested in adjuvant trials has shown proven effectiveness against established metastatic uveal melanoma when administered systemically, there is little reason for optimism regarding any of them.

\section{Surveillance Testing for Metastasis}

Many, if not most, patients with primary uveal melanoma are currently advised to undergo regular periodic surveillance testing for metastasis following excision of the primary tumor (e.g., enucleation, trans-scleral tumor resection) or obliterative treatment of the tumor (e.g., plaque radiation therapy, proton beam irradiation).

Although surveillance testing clearly identifies a higher percentage of the patients who eventually develop metastasis at an asymptomatic, limited substage of their metastasis than does systemic evaluation prompted by tumor-induced symptoms ${ }^{27-29}$ and although patients with limited substage metastasis clearly have a longer life expectancy after initial detection of the metastasis than do patients with advanced substage metastasis, ${ }^{30}$ there is really no evidence that performing frequent and/or intensive surveillance testing for metastasis really improves our patients' survival. ${ }^{31,32}$ Consequently, we do not currently advocate regular periodic surveillance testing for metastatic uveal melanoma except in patients enrolled in prospective clinical trials. 
1. Augsburger JJ, Damato BE, Bornfeld N, Uveal Melanoma. In: Yanoff MD, Duker JS (eds), Ophthalmology, 3rd edn, Mosby Elsevier, 2009;895-905.

2. Kujala E, Makitie T, Kivela T, Very long-term prognosis of patients with malignant uveal melanoma, Invest Ophthalmol Vis Sci, 2003;44(11):4651-9

3. Singh $A D$, Topham A, Survival rates with uveal melanoma in the United States: 1973-1997, Ophthalmology, 2003;110(5):962-5.

4. Pantel K, Brakenhoff RH, Dissecting the metastatic cascade, Nat Rev Cancer, 2004;4(6):448-56.

5. Augsburger JJ, Gamel JW, Clinical prognostic factors in patients with posterior uveal malignant melanoma, Cancer, 1990;66(7):1596-600.

6. Mooy CM, De Jong PT, Prognostic parameters in uveal melanoma: a review, Surv Ophthalmol, 1996;41(3):215-28.

7. Augsburger JJ, Schroeder RP, Territo C, et al., Clinical parameters predictive of enlargement of melanocytic choroidal lesions, Br J Ophthalmol, 1989;73(11):911-7.

8. Seddon JM, Polivogianis L, Hsieh CC, et al., Death from uveal melanoma. Number of epithelioid cells and inverse SD of nucleolar area as prognostic factors, Arch Ophthalmol 1987;105(6):801-6

9. Scholes AG, Damato BE, Nunn J, et al., Monosomy 3 in uveal melanoma: correlation with clinical and histologic predictors of survival, Invest Ophthalmol Vis Sci, 2003;44(3):1008-11.

10. Horsman DE, Sroka H, Rootman J, White VA, Monosomy 3 and isochromosome $8 \mathrm{q}$ in a uveal melanoma, Cancer Genet Cytogenet, 1990:45(2):249-53

11. Sisley K, Rennie IG, Cottam DW, et al., Cytogenetic findings in six posterior uveal melanomas: involvement of chromosomes 3, 6, and 8, Genes Chromosomes Cancer, 1990;2(3):205-9.

12. Harbour JW, Molecular prognostic testing in uveal melanoma: has it finally come of age?, Arch Ophthalmol, 2007;125(8):1122-3.
13. Ehlers JP, Worley L, Onken MD, Harbour JW, Integrative genomic analysis of aneuploidy in uveal melanoma, Clin Cancer Res, 2008;14(1):115-22

14. Augsburger JJ, Correa ZM, Schneider S, et al., Diagnostic transvitreal fine-needle aspiration biopsy of small melanocytic choroidal tumors in nevus versus melanoma category, Trans Am Ophthalmol Soc, 2002;100:225-32; discussion 232-4.

15. Tschentscher F, Husing J, Holter $\mathrm{T}$, et al., Tumor classification based on gene expression profiling shows that uveal melanomas with and without monosomy 3 represent two distinct entities, Cancer Res, 2003;63(10):2578-84.

16. Onken MD, Worley LA, Harbour JW, A metastasis modifier locus on human chromosome $8 p$ in uveal melanoma identified by integrative genomic analysis, Clin Cancer Res, 2008;14(12):3737-45.

17. Onken M, Worley LA, Long MD, et al., Oncogenic mutations in GNAQ occur early in uveal melanoma, Invest Ophthalmol Vis Sci. 2008;49(12):5230-4

18. Mocellin S, Rossi CR, The melanoma molecular map project, Melanoma Res, 2008;18(3):163-5.

19. Woll E, Bedikian A, Legha SS, Uveal melanoma: natural history and treatment options for metastatic disease, Melanoma Res, 1999;9(6):575-81.

20. Augsburger JJ, Corrêa ZM, Shaikh AH, Quality of evidence about effectiveness of treatments for metastatic uveal melanoma, Trans Am Ophthalmol SOC, 2008:106:128-35; discussion 135-7.

21. Rivoire $M$, Kodjikian L, Baldo $S$, et al., Treatment of liver metastases from uveal melanoma, Ann surg oncol, 2005;12(6):422-8.

22. Bedikian AY, Legha SS, Mavligit G, et al., Treatment of uveal melanoma metastatic to the liver: a review of the $M$. D. Anderson Cancer Center experience and prognostic factors, Cancer, 1995;76(9):1665-70.

23. Fong $\mathrm{Y}$, Fortner J, Sun RL, et al., Clinical score for predicting recurrence after hepatic resection for metastatic colorectal cancer: analysis of 1001 consecutive cases, Ann Surg, 1999;230(3):309-18; discussion 318-21.

24. Pereira PR, Odashiro AN, Marshall JC, et al., The role of C-kit and imatinib mesylate in uveal melanoma, J Carcinog, 2005;4:19.

25. Kadenhe-Chiweshe A, Papa J, McCrudden KW, et al., Sustained VEGF blockade results in microenvironmental sequestration of VEGF by tumors and persistent VEGF receptor-2 activation, Mol Cancer Res, 2008;6(1):1-9.

26. Wedge SR, Kendrew J, Hennequin LF, et al., AZD2171: a highly potent, orally bioavailable, vascular endothelial growth factor receptor-2 tyrosine kinase inhibitor for the treatment of cancer Cancer Res, 2005:65(10):4389-400.

27. Diener-West M, Reynolds SM, Agugliaro DJ, et al., Development of metastatic disease after enrollment in the COMS trials for treatment of choroidal melanoma: Collaborative Ocular Melanoma Study Group Report No. 26, Arch Ophthalmol, 2005;123(12):1639-43.

28. Diener-West M, Reynolds SM, Agugliaro DJ, et al., Screening for metastasis from choroidal melanoma: the Collaborative Ocular Melanoma Study Group Report 23, I Clin Oncol 2004;22(12):2438-44.

29. Kaiserman I, Amer R, Pe'er J, Liver function tests in metastatic uveal melanoma, Am J Ophthalmol, 2004;137(2):236-43.

30. Eskelin S, Pyrhonen $\mathrm{S}$, Summanen $\mathrm{P}$, et al., Screening for metastatic malignant melanoma of the uvea revisited, Cancer, 1999;85(5):1151-9.

31. Rietschel P, Panageas KS, Hanlon C, et al., Variates of survival in metastatic uveal melanoma, J Clin Oncol 2005;23(31):8076-80.

32. Maeda T, Tateishi U, Suzuki S, et al., Magnetic resonance screening trial for hepatic metastasis in patients with locally controlled choroidal melanoma, Jpn I Clin Oncol, 2007:37(4):282-6. 